\title{
Um Corpo Sensível à Transcendência: Uma compreensão mística da sensibilidade
} A Body Sensitive for Transcendence:
A Mystical Understanding of Sensibility

DOI:10.12957/ek.2015.21464

Dra. Jonna Bornemark jonna.bornemark@sh.se Universidade de Södertörn - Suécia tradução Dndo. Marc Machado Franken marcmachadofranken@gmail.com

UERJ

$\mathrm{Na}$ fenomenologia e na filosofia existencial, a relação com o divino fora entendida como intimamente relacionada à capacidade humana à transcendência. Esta compreensão pode ser salientada a partir da leitura de Das fließende Licht der Gotheit ${ }^{* *}$, da beguina Mechthild von Magdeburg, um texto da mística cristã no qual o corpo, a sensibilidade e o encontro erótico com o divino são centrais. Aqui, a sensibilidade é entendida como o lugar de encontro entre a alma e Deus. O presente artigo almeja contribuir para uma fenomenologia da experiência religiosa na qual a capacidade humana para a transcendência e a corporeidade humana são pensadas como entrelaçadas.

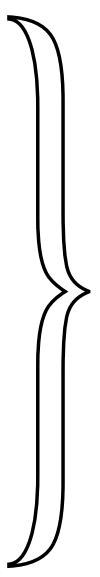

PALAVRAS-CHAVE

Fenomenologia. Filosofia Existencial. Mística Feminina. Misticismo. Mechthilde von Magdeburg. Beguinas. Corpo. Corporeidade. Sentidos. Transcendência

\footnotetext{
*Nota dos editores: Artigo originalmente publicado em: Embodied Religion. Proceednings of the 2012 Conference of the European Society for Philosophy of Religion, Utrecht: Ars Disputandi, eds. Peter Jonkers \& Marcel Sarot, 2013, p. 25-46. Agradecemos a autora pela gentileza em enviar o texto para a tradução e publicação na revista Ekstasis.

**N.T: Trata-se do nome original do texto utilizado como base pela autora para a escritura deste artigo. Todavia, em virtude do fato de não haver nenhuma tradução para a lingua portuguesa do mesmo, pareceu-me mais adequado manter o nome original ao longo deste trabalho, visto que, com isto, evita-se o erro de nos comprometermos com uma obra inexistente e mantem-se aberta, portanto, a possibilidade de interpretação das passagens, o que, ao meu ver, favorece a discussão proposta. Isto dito, vale ressaltar que, no presente texto, todas as passagens traduzidas para o português são livres e foram feitas a partir das duas matrizes encontradas. Para tanto, a título de comparação, mantive junto a todas as versões em português duas outras versões: a proposta pela autora - em inglês - e a original. A título de ilustração, contudo, esboça-se, aqui, uma tradução livre do título do texto para o português que fica da seguinte forma: A fluente luz da divindade.
} 


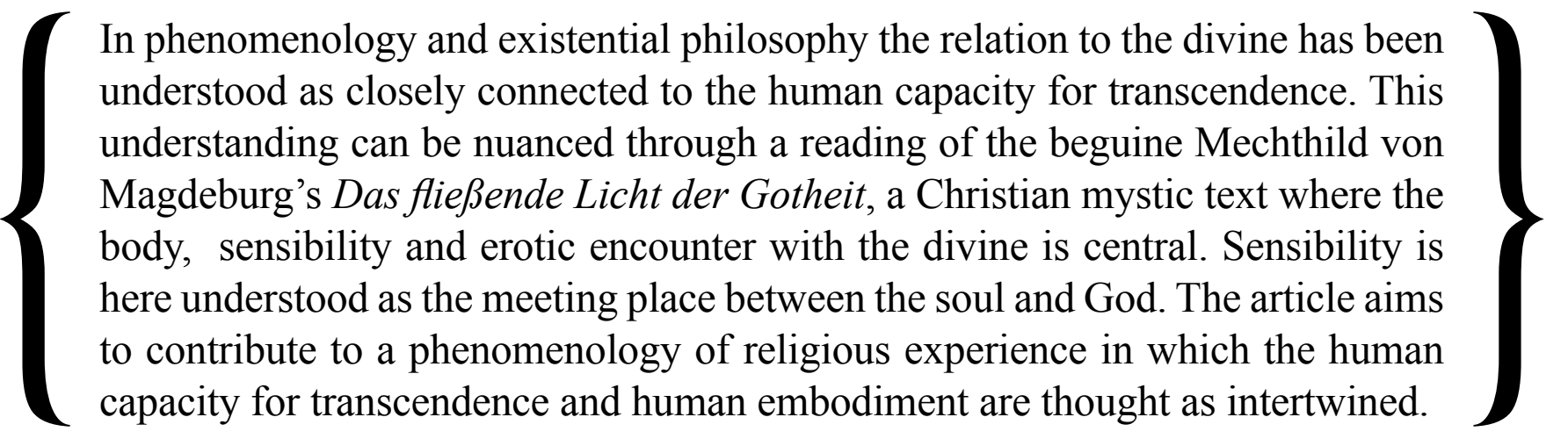

Phenomenology. Existential Philosophy. Female Mystics. Mysticism. KEY-WORDS Mechthild von Magdeburg. Beguines. Body. Embodiment. Senses. Transcendence 


\section{Introdução}

Em tradições monoteístas, a religião foi mais comumente entendida como uma questão espiritual e tanto a religiosidade quanto a espiritualidade são compreendidas como conceitos proximamente relacionados. Mesmo que qualquer religião, enquanto prática, tenha, necessariamente, dimensões corporais bastante fortes, o corpo - na teoria e nos escritos - nem sempre teve uma posição muito forte. $\mathrm{O}$ cristianismo, por exemplo, tem um pé fundado na tradição neoplatônica onde o corpo é entendido como a prisão da fagulha divina da alma, o que impede a alma de voltar à sua origem divina.

Na filosofia moderna, o corpo foi entendido como extensão, um objeto material dentre outros, e como aquilo que está presente aqui e agora. Tais idéias foram profundamente questionadas na filosofia mais contemporânea - pós- moderna - que quer reavaliar o corpo. Ao mesmo tempo, na fenomenologia e filosofia existencial da religião, foi-se implicitamente argumentado de que há uma razão para a prioridade da alma, visto que a religião nasce da capacidade humana para a transcendência; do transbordamento do aqui e agora. Esta situação coloca a pergunta: que posição tem o corpo em relação à capacidade humana para transcendência?

Nas religiões abraâmicas, a capacidade para a transcendência foi transformada em uma capacidade de transgredir o mundo atual, uma habilidade que deveria ser excepcionalmente forte na, assim chamada, tradição mística. Na filosofia, tradições místicas são comumente acusadas de tentar achar aquela unidade harmoniosa, pura e pacífica com o divino na qual todos os problemas do mundo e do corpo são, de uma vez por todas, deixados para trás. Tal compreensão das tradições místicas pode ser encontrada ao longo da filosofia contemporânea, explicitamente, por exemplo, em Karl Jaspers e Iris Murdoch1. E, muito embora a capacidade para a transcendência - aqui lida como uma capacidade positiva e sumamente humana - esteja no centro daquilo que se chamou de virada para a religião dentro da fenomenologia, aqui também, o corpo tende a ser esquecido. Nas análises fenomenológicas, a atenção foi primariamente dada aos místicos cristãos. Mas se estamos interessados na relação entre transcendência e corpo, talvez devêssemos virar para uma tradição proximamente relacionada, embora ligeiramente diversa: a tradição feminina da mística.

1 Ver Karl Jaspers, Philosophy Vol.1, (Chicago, 1969) e Iris Murdoch, Existencialists and Mystics: Writings on Philosophy and Literature (Londres, 1997). 
Historiadores como Caroline Bynum e Amy Hollywood apontaram que é justamente a relação com o corpo que diferencia os escritos destas místicas². Enquanto mulheres, as místicas foram associadas com o corpo de uma maneira mais íntima que os místicos. A figura de Cristo como o Deus que se torna corpo é mais importante para as místicas e a questão da corporeidade está mais presente em seus textos. Quando as escritoras místicas enfatizam a relação positiva entre o corpo e o divino, o corpo de Jesus se torna a porta de entrada para uma relação íntima com o divino, mais evidente na sagrada comunhão. Ao sangrar, o seu corpo alimenta e dá vida à humanidade. Durante o período medieval, o feminino foi relacionado ao sangue tanto através do sangue menstrual - que era entendido como o material a partir do qual a criança era feita - e a crença de que o sangue poderia ser transformado em leite materno. O corpo feminino é o corpo perfurado, que dá vida e que está aberto aos outros. O corpo de Cristo, com seu estigma sangrento, se relaciona a estes aspectos do corpo feminino: as suas dores se assemelhavam à dor do parto, ele estava alimentando a humanidade com seu estigma e ele se deu aos humanos assim como uma mãe se dá ao seu bebê. Capacidades sagradas podiam, portanto, se relacionar às habilidades do corpo feminino. O leite materno de mulheres santas podiam curar os doentes, corpos femininos se abriam em estigmas mais frequentemente que os masculinos, e algumas mulheres, como Sta. Brígida da Suécia, receberam o chamado de Deus sob a forma do movimento de um feto no útero. Porém, a diferença de gênero não é, de todo, um divisor de águas: místicos como Bernardo de Claraval também utilizavam estratégias femininas similares, se chamavam de noivas de Deus e se identificavam com Maria.

O corpo está intimamente relacionado aos sentidos, como fora mostrado na tradição fenomenológica. O corpo é, até mesmo, constituído através de sua sensibilidade e sua capacidade de tanto ser sentido quanto de sentir. Os sentidos, evidentemente, sempre foram fontes de conhecimento, mas durante a alta idade média eles foram considerados como uma fonte não confiável no que tange à relação com o divino. $\mathrm{O}$ que chamamos de tradição mística fora, até o século XII, uma tradição de interpretação textual por vias meramente intelectuais. Foram especialmente as místicas, dentro do forte movimento religioso do século XII e XIII, que deram aos sentidos uma posição diferente. Místicas como Hildegarda de Bingen (1098-1179) ganharam seu conhecimento do divino através dos sentidos, comumente em visões baseadas na vista, na audição, no olfato etc.

2Caroline Bynum, Fragmentation and Redemption: Essays on Gender and the Human Body (New York 1991), 194 e Amy Hollywood, The Soul as Virgin Wife: Mechthild of Magdeburg, Marguerite Porete and Meister Eckhart (Notre Dame/London 1995), 25. 
Mas isto as fez estranhas aos olhos dos outros místicos. Por exemplo Mestre Eckhart (1260-1328) e Johannes Tauler (1300-1361), que, em ampla medida, foram influenciados pelas místicas, foram críticos em relação à sua dependência nos sentidos ${ }^{3}$. Eles preferiam a speculatio dos sábios à visio dos devotos, dado que estes sentidos podiam ser traiçoeiros: talvez a visão tivesse vindo do diabo, ao invés do divino. Pelo contrário, eles consideravam a razão como a única fonte de conhecimento confiável.

No presente artigo, voltarei a minha atenção para como o corpo vivo e sensível é tematizado na tradição mística feminina. Começarei com um breve resumo da filosofia e fenomenologia da religião onde a religião é tomada como uma consequência da capacidade humana para a transcendência e da prioridade da alma em detrimento do corpo. Por conseguinte, eu voltarei para Das fließende Licht der Gotheit, um texto cristão e místico do século XIII escrito por Mechthild von Magdeburg. Aqui, aos sentidos, bem como ao corpo humano, são dados papéis cruciais na relação com o divino. O meu foco central estará na relação entre a capacidade para a transcendência e o corpo sensível.

\section{Religião como a capacidade humana para a transcendência}

$\mathrm{Na}$ fenomenologia moderna, assim como na filosofia existencial, a habilidade de vivenciar a negatividade é central ao ser humano ${ }^{4}$. Tal habilidade é, sem dúvida, paradoxal, visto que a sua negatividade é presente e sua presença é uma ausência. Todavia, ela não é uma experiência extraordinária, mas algo presente no dia-a-dia. O mundo não seria um mundo se nós apenas vivenciássemos pura presença e nenhuma negatividade. Neste sentido, nós não aceitaríamos que uma casa tem os seus fundos, caso não tomássemos conhecimento deles no momento. Nem, tampouco, reconheceríamos uma outra pessoa como existente, visto que nunca podemos vivenciar suas vivências. O agora inclui, portanto, não apenas o que é presente, mas também o passado, bem como expectativas para o futuro. Esta capacidade para a negatividade nos garante, na infância mais remota, a

3 Isto fora discutido por, entre outros, Friedrich-Wilhelm Wentzlaff-Eggebert em Deutsche Mystik zwischen Mittelalter und Neuzeit: Einheit und Wandlung ihrer Erscheinungsformen (Berlin 1969), ver, especialmente, 113.

4 Neste capítulo, tomamos como base Søren Kierkegaard, The Concept of Anxiety (Princeton 1981 [1844]); Max Scheler, The Human Place in the Cosmos (Evanston 2009 [1928]); Edmund Husserl, On the Phenomenology of the Consciousness of Internal Time [1893-1917] (Dordrecht, 1991); e Simone de Beauvoir, The Ethics of Ambiguity (Secaucus, 1948) etc. 
forma mais simples de brincadeira: esconde-esconde. Nesta brincadeira, os pais, por exemplo, colocam as suas mãos à frente de seus rostos e, então, afastam-nas e revelam a suas faces. $\mathrm{O}$ objetivo da brincadeira não é que o bebê veja, alternadamente, o dorso das mãos e o rosto dos pais. Pelo contrário, o que ele vê é a presença e a ausência do pai ou da mãe. A parte curiosa jaz na lembrança e na expectativa pelos pais, que são interrompidas pela presença dos pais. Como tal, é uma brincadeira baseada naquilo que não está presente, mas que é, ainda assim, mostrado no presente. A expectativa é, de modo similar, a forte e, por vezes, esmagadora presença daquilo que está ausente. O ser humano distingue-se pelo uso e desenvolvimento desta capacidade, uma capacidade que torna possível a alguém planejar e alterar ambos seus arredores e sua vida. Ela também possibilita que o ser humano olhe para si mesmo de fora e reflita sobre si mesmo. Para planejar, ele precisa do espaço livre constituído através da descoberta de que a vida pode ser diferente e, para poder refletir sobre si mesmo, ele precisa negar a plena presença ela mesma. Talvez esta última capacidade seja a mais estranha. Como é possível a ele ver a si mesmo ao mesmo tempo que é ele quem vê? Uma resposta fenomenológica, a de Husserl, seria que é possível, visto que o ser humano é um ser temporal e intencional continuamente direcionado ao mundo e, então, constitui objetos. Isto quer dizer que ele não os cria, mas os constitui como objetos. Ao se voltar para si mesmo, o si mesmo é tanto constituído como um objeto quanto como o objeto constituidor, ou seja, como corpo e alma.

O corpo é, portanto, parte do mundo e está sujeito a todas as suas leis. A alma, por outro lado, denota a possibilidade discutida acima e transcende aquilo que é dado no presente. Ela inclui livre-arbítrio, criatividade e a habilidade de refletir. $\mathrm{Na}$ filosofia existencial, o ser humano é, até mesmo, associado a estas capacidades de exceder o estado atual e a situação, ou seja, com sua transcendência. Mas se o corpo define o ser humano enquanto parte do mundo - enquanto aqui e agora e enquanto um objeto dentre outros tantos -, aonde pertence a alma? Onde se encontra a alma quando ela olha a si mesma e, então, transforma-se em um objeto? Ela não pode ser parte do mundo, dado que, tão logo ela se vê como um objeto dentre outros tantos, ela já não é mais a alma que vivencia. Por esta razão, a alma não pode ser parte do mundo e a necessidade de formular uma outra posição - uma posição não mundana - nasce. Ainda assim, a alma ainda depende do corpo e o mundo ainda limita o seu livre movimento. Tal falta de poder da transcendência humana produz a idéia de um poder puramente transcendente. $\mathrm{E}$, visto que o movimento da alma define a vida humana e o seu poder constituidor, uma pura transcendência seria, também, a fonte de toda vida e, como um solo transcendente. Mas o que, exatamente, não é parte do mundo, nem um objeto 
dentre outros, é uma transcendência transcendente. Ela é a origem para toda vida em particular, mas não é, ela mesma, uma criatura em particular. Como tal, ela pode ser entendida como dada pelo mundo, mas nunca dada nela mesma. Portanto, o divino não é inesgotável ou inalcançável (dentro do mundo) - e, por isto, impossível de se compreender ou descrever plenamente - já que a compreensão, assim como a linguagem, é adaptada à aparição no mundo.

Neste sentido, a filosofia existencial e a fenomenológica tentam entender como a 'alma' está separada do 'corpo' e 'o divino' do 'mundano'. A tradição fenomenológica também tem reflexões importantes acerca da corporeidade, sobretudo Edmund Husserl e Maurice Merleau-Ponty, mas nenhum deles teve um interesse significativo na filosofia da religião. Ademais, os pensadores conhecidos por suas reflexões religiosas, como Edith Stein, Max Scheler e Michel Henry, têm análises curiosas sobre a corporeidade, mas, quando eles se voltam à religião, o tema do corpo é deixado de lado e a transcendência se torna a sua única busca ${ }^{5}$. Em resumo: Na fenomenologia e na filosofia existencial o divino está intimamente conectado à capacidade humana para transcendência e suas pressuposições transcendentais. Eu considero, é verdade, que esta é uma contribuição à compreensão filosófica da religião, mas ela também é insuficiente em sua tendência de estreitar ainda mais a compreensão do corpo e o lugar da corporeidade. Ao me lançar nestas teorias fenomenológicas e examinar minuciosamente textos religiosos nos quais à corporeidade e à sensibilidade são dados papéis diversos, espero contribuir para uma compreensão mais refinada da relação entre transcendência e corporeidade. Ao longo deste texto, desenvolverei isto através da leitura de Mechthilde von Magdeburg e seu texto Das fließende Licht der Gotheit.

\section{Entrelaçamento sensível}

Mechthild pertenceu ao movimento beguino, que fora, durante os séculos XII e XIII, parte da (então em rápida expansão) religiosidade feminina na Europa. As beguinas não faziam votos monásticos e permaneciam na cidade, em seus próprios aposentos. À exceção do dinheiro que algumas delas traziam consigo quando se juntavam à casa, as beguinas tiravam o seu sustento cuidando dos mor-

5 Eu desenvolvo este argumento em 'Ambiguities of the human body in phenomenology and Christian mysticism' in Ola Sigurdson, Marius Timmann Mjaaland \& Sigridur Torgeirsdottir (eds.), The Body Unbound: Philosophical Perspectives on Religion, Embodiment, and Politics (Cambridge 2010), 73-88. 
tos, como enfermeiras, como professoras, na indústria têxtil etc. Suas vidas eram menos reguladas que a das freiras e mais mundanas, no sentido que elas tinham mais contato com os leigos. Mechthild provavelmente foi a líder de uma tal casa em Magdeburg. Ela nasceu entre 1207 e 1210 e morreu entre 1282 e 1294.

Das fließende Licht der Gotheit é um texto que pertence à tradição mística na medida em que é inspirado, por exemplo, por Hildegarda de Bingen e Santo Agostinho. O Deus de Mechthild, porém, não está apenas associado à capacidade para a transcendência e o corpo não é, em seus escritos, algo que deva ser descartado na busca por Deus. Pelo contrário, como já fora ressaltado por diversos estudiosos em várias áreas, sua obra é permeada por uma linguagem sensorial rica e por um profundo erotismo. Os sentidos não são algo a ser negado, mas uma porta de entrada para Deus e um conjunto de capacidades que devem ser refinadas ${ }^{6}$. Seus textos, os quais descrevem uma relação pessoal com o divino, contêm poemas, histórias e, talvez mais digno de nota, diálogos entre personificações do amor e os sentidos etc. Ou, como no parágrafo seguinte, entre a alma e Deus:
Alma:
Senhor, tu és o sol a todos os olhos;
Tu és o deleite de todos os ouvidos;
Tu és a voz de todas as palavras;
Tu és a força de toda piedade;
Tu és o ensinamento de toda sabedoria;
Tu és a vida de todas as vidas;
Tu és o ordenamento de todos os seres!
$[\ldots]$
Deus:
Tu és uma luz para os meus olhos;
Tu és uma lira aos meus ouvidos;
Tu és uma voz para minhas palavras;
Tu és uma projeção da minha piedade;
Tu és uma glória em minha inteligência;
Tu és uma vida em minha vivacidade;
Tu és um louvor no meu Ser!

6 Ver, por exemplo, a dissertação de Marilyn Webster, Mechthild von Magdeburgs Vocabulary of the Senses, (Amherst 1996); Margot Schmidt, Versinnlichte Transzendenz bei Mechthild von Magdeburg, in: Dietrich Schmidtke (ed.), Minnichlichiu gotes erkennusee: Studien zur frühen abendländischen Mystiktradition (Stuttgart-Bad Cannstatt 1990), 61-88; Elizabeth Alvilda Petroff, Body and Soul: Essays on Medieval Women and Mysticism (New York 1994); Kurt Ruh, Beginenmystik: Hadewijch, Mechthild von Magdeburg, Marguerite Porete, Zeitschrift für Deutsches Altertum und Deutsche Literatur 106 (1977), 265-277. 
$(\mathrm{III}: 2)^{7}$

Esta descrição poderia ser compreendida como uma versão mitológica e dramatizada de uma posição filosófica. Pode-se dizer que descreve a relação entre o pressuposto transcendental e transcendente (Deus) e o indivíduo (a alma). Deste modo, ela articula a relação entre o contínuo e o descontínuo. Estes dois, no entanto, não são domínios separados. Pelo contrário, o texto mostra um forte entrelaçamento entre Deus e a alma, ainda que se exija uma inspeção minuciosa para que ele seja plenamente compreendido. Cada fala no discurso de Deus à alma corresponde, tematicamente, a uma fala no discurso da alma. A seguir, eu analisarei alguns destes pares temáticos.

Senhor, tu és o sol a todos os olhos; Tu [a alma] és a luz para os meus olhos.

A relação entre Deus e a alma é abordada a partir de duas perspectivas: a divina e a humana. Em cada fala, ambas as posições são consideradas, resultando em uma descrição quádrupla da visão. Destarte, Deus, enquanto luz do sol, é descrito como o pressuposto para o ver e, portanto, como a possibilidade dos seres verem. A alma, por outro lado, é um ser visível aos olhos de Deus. A alma tem uma natureza dupla, visto que ela é visível e pode ver: visível ante a Deus e capaz de ver graças a Deus. Alguém poderia se surpreender de a alma ser visível, dado que isto não parece corresponder à idéia de alma como a capacidade transcendente apresentada acima. Mas, em verdade, em Mechthild, eu proporia que a alma é aquela parte do ser humano que está em diálogo (ou resistindo ao diálogo) com Deus. A alma é, exatamente como na análise fenomenológica, a vida do ser humano, mas esta alma pode ser vista e, como tal, é chamada 'cor-

7 Texto original: Herre, du bist die sunne aller ogen, du bist der lust aller oren, du bist dú stimme aller worten, du bist dú kraft aller vromekeit, du bist dú lere aller wisheit, du bist das lip in allem lebende, du bist dú ordenunge alles wesendes! [ ] Du bist ein lieht vor minen ogen, du bist ein lire vor minen oren, du bist ein stimme miner worten, du bist ein meinunge miner vromekeit, du bist ein ere miner wisheit, du bist ein lip in minem lebende, du bist ein lop in minem wesende! [III:2] Das fließende Licht der Gottheit, ed. Gisela Vollmann-Profe, (Frankfurt aM 2003). Todas as traduções em inglês foram tiradas de The Flowing Light of the Godhead, traduzida por Frank Tobin (New York 1998).

Tradução para o inglês: Soul: Lord, you are the sun for all eyes; You are the delight of all ears; You are the voice of all words; You are the force of all piety; You are the teaching of all wisdom; You are the life of all that lives; You are the ordering of all beings. [ ] God: You are a light to my eyes; You are a lyre to my ears; You are a voice for my words; You are a projection of my piety; You are one glory in my wisdom, you are one life in my liveliness, you are a praise in my Being! [III:2] 
po'. Ela é caracterizada, justamente, por sua possibilidade de ser vista, mas é vista como uma luz, ou seja, como um visto capaz de ver.

O divino não mostra este caráter duplo da visão - ambos capaz de ver e visto -, mas tem uma natureza dupla de outro tipo: ele é ambos um ver e o pressuposto para o ver da alma. Como tal, o divino necessita da visibilidade da alma, da visibilidade dos seres, dos quais o divino não faz parte. Os seres visíveis constituem o ver do divino, já que o ver não pode existir sem algo visto. A alma necessita do divino e o divino de algo para ver. Isto quer dizer que o divino não necessita de um ser específico, mas, em todo caso, de seres enquanto tais. Então, como o ver do divino deve ser compreendido, quando o divino não é um ser visível em um único lugar e, portanto, não é um ser com uma perspectiva específica? Poderíamos compreendê-lo como uma espécie de visão anônima, visto que ele vem de todos os lugares e não de um lugar específico. Ele inclui a possibilidade do visto de ser visto e, como tal, é uma capacidade anônima de ser visto que vai para além de um ver individual. Este entrelaçamento entre e ver e visto é reminiscente da filosofia da sensibilidade de Merleau-Ponty, já que inclui os mesmos componentes ${ }^{8}$. Deus como pressuposto, bem como o ver de Deus é - assim como o anonimato em Merleau-Ponty - o ver que vai para além do indivíduo e um elemento dentro do qual o indivíduo pode ver. A alma como uma 'luz' para os olhos de Deus, é, assim como todos os seres sensíveis, um ver visto e um visto capaz de ver. Mas será que isto significa que nós devemos compreender o ver de Deus apenas como este ver anônimo ou ele tem uma posição privilegiada e, portanto, sua própria perspectiva? Em outro verso ela faz alusão a João 8:12 (Eu sou a luz do mundo) dizendo:

O meu amante então falou desta forma: 'Eu hei de pôr a luz dentro da lanterna e, para todos aqueles cujos olhos olharem para a luz, um raio especial brilhará da luz para dentro do olho de sua sabedoria.'

A alma então pergunta com grande passividade, mas sem medo: 'Queridíssimo, o que significa a lanterna?' O nosso Senhor disse: 'Eu sou a luz e o teu seio é a lanterna.' (III:12) ${ }^{9}$

8 Ver especialmente 'The Intertwining: The Chiasm' in: The Visible and the Invisible (Evanston 1968).

9 Texto original: Ich wil das lieht uf den lúhter setzen und allú dú ogen, dú das lieht angesehent, den sol ein sunderlich strale schinen in das oge ir bekantnisse von dem liehte. Do vragete du sele mit grosser undertenekeit ane vorhte: Vil lieber, wer sol der lúchter sin? Do sprach únser 
Nesta passagem fica claro que Deus é a luz enquanto tal e que, para que haja visão, Ele precisa ter uma lanterna que possa ser acesa. Aqui, o ver é constituído através da colaboração entre a luz de Deus e a lanterna humana. Deus ilumina a lanterna humana e todos aqueles que vêem esta luz e - alguém poderia acrescentar - a contemplam recebem a luz em outro nível, a luz no olho da sabedoria. Eu diria que este verso, não apenas tematiza um conhecimento específico do divino - e nem, tampouco, que a luz é usada de modo metafórico -, mas que, ao contrário, ela conecta o ver dos olhos com o ver do entendimento. Ver Deus como um ser entre muitos é impossível. Assim como o sol é esta luz divina que cega. Ver os pressupostos é como tentar ver o sol, onde a luz se torna tão clara que destrói a visão. No entanto, isto não significa que os sentidos devam ser abandonados. Pelo contrário, a relação entre Deus e a alma pode ser entendida como um entrelaçamento mútuo através do qual eles criam o elemento do ver.

Em um outro verso, Mechthild diz sobre a alma: 'Na mais bela luz, ela é cega a si mesma e, na maior de todas as cegueiras, sua visão é a mais clara' (I:22). ${ }^{10}$ Para que ela possa se relacionar com Deus, poder-se-ia argumentar, ela precisa considerar a luz ela mesma, não apenas o que é visível. Em tal meditação ela se torna cega a si mesma (como um ser mundano 'visto'), mas também compreende si mesma (como capaz de ver) da forma mais clara de todas. Aqui, a 'visão' claramente brinca com a relação entre visibilidade e o uso mais metafórico de 'entendimento'. Entretanto, ao fazer isto - na mudança de visibilidade - ela parte do ver cotidiano, dos sentidos, e, para que possa 'ver' esta capacidade, o ver é transformado, uma invisibilidade ao ver comum prepara o caminho para outro tipo de ver. Então isto não inclui a passagem do mundo para uma outra região 'celestial'? Eu diria que não, visto que esta outra visão está inclusa na visão cotidiana. Não é um distanciamento dos sentidos, mas um movimento para dentro dos sentidos. E é dentro de suas capacidades de ver que ela encontra seu Deus. Sem os sentidos não há um ponto de encontro para ambos.

As passagens a seguir incluem padrões parecidos e os próximos dois trechos incluem discussões sobre os sentidos, embora aqui o ouvir e o falar estejam no centro.

herre: Ich bin das lieht und din brust ist der lúhter. [III:12]

Tradução para o inglês: I shall place the light onto the lantern, and for all those that whose eyes look upon the light a special beam shall shine from the light into the eye of their knowledge. The soul then asked with great submissiveness but without fear: Dearest, what is the lantern supposed to be? Our Lord said: I am the light and your breast is the lantern.[III:12]

10 'in dem schonsten liehte ist si [die brut] blint an ir selber und in der groston blintheit sihet si allerklarost.' [I:22] 
Tu és o deleite de todos os ouvidos; Tu és a lira aos meus ouvidos;

Esta fala aponta para o deleite dos sentidos. Os sentidos não são algo negativo do qual a alma deva escapar, mas o meio através do qual Deus e Mechthild estão em contato um com o outro, embora de formas radicalmente diferentes. Através dos sentidos, eles desfrutam um do outro. Deus é a alegria, o prazer da possibilidade de ouvir e o indivíduo é a música no ouvido de Deus. Eles desfrutam do outro no compartilhamento dos sentidos. Isto mostra uma dependência mútua, mas também uma relação assimétrica. Eles fazem parte da mesma tecelagem; ambos são, ou têm, olhos/orelhas/palavras - e, juntos, eles constituem e desfrutam destes fenômenos.

Cada fala neste verso segue o mesmo padrão e merece ser analisado, mas eu encerrarei a discussão deste verso com algumas palavras da última fala:

Tu és o ordenamento de todos os seres; Tu és um louvor no meu Ser!

Esta fala pode ser entendida como articulando o que Heidegger chamou de diferença ontológica que, em uma das versões formuladas por Heidegger, seria a diferença entre os seres e o ser dos seres. Aqui, Deus é entendido como a ordem e a estrutura de todos os seres e a alma como um ser que celebra o Ser de Deus. É, portanto, ordem e celebração que se relacionam entre si em relação ao ser. É interessante que ela aqui relaciona um conceito (ordenamento) que nós entendemos como metafísico com um que pertence à esfera religiosa (louvor) e anuncia a próxima parte do mesmo verso.

\section{O Corpo como ponto de encontro}

Acima eu me utilizei do conceito de anonimato de Merleau-Ponty. Mas o Deus de Mechthild não é anônimo. Ele não é, como nós vimos, uma instância metafísica distante, mas a sua relação é o desfruto da vida, que deveria ser celebrado e investigado junto a todos os modos humanos. Deus não é, essencialmente, uma instância metafísica que exija uma explicação racional, mas está relacionado a todas as camadas do ser humano. Tampouco, é o divino um ser 
que o ser humano poderia controlar ou conhecer plenamente. Neste sentido, ele é, sempre, transbordante. Mas este transbordamento não o torna distante; sua presença transbordante tem lugar no corpo. Isto nos leva à segunda parte do verso acima mencionado onde a alma diz:

- Senhor, tu estás constantemente perdido de amor por $\operatorname{mim}$;

Isto já me mostraste pessoalmente.

Inscreveste-me em teu livro da Divindade;

Pintaste-me em tua humanidade;

Enterraste-me em tua lateral, em tuas mãos e pés.

Oh, permiti-me, queridíssimo, verter bálsamo sobre ti.

- Oh, querida ao meu coração, onde acharás o bálsamo?

- Senhor, eu dilaceraria o coração de minha alma em dois e pretendia colocar-te nele.

- Tu não poderias jamais dar-me um bálsamo mais relaxante que deixar-me incessantemente deitar, sem peso, em tua alma.

- Senhor, se me levasses para casa contigo, eu seria, eternamente, tua médica.

- Sim, isto, eu quero. [...](III:2) ${ }^{11}$

A segunda parte, bem como a estrutura de todo o diálogo, apresenta um quadro relativamente diferente da primeira. Aqui, o 'anonimato' se torna uma categoria ainda menos apropriada, visto que a instância metafísica está apaixonada pela alma. O entrelaçamento da primeira parte é ainda mais enfatizado aqui e é alocado na carne. Se a primeira metade descreve uma relação positiva e criadora, discutida em termos positivos que celebram a diferença entre eles, a segunda metade mostra uma tensão e uma ânsia por superar o fosso criacional entre eles.

Aqui é Deus que é a parte mais fraca. Apesar de ele ser o pressuposto, ele

11Texto original:- Herre, du bist ze allen ziten minnensiech na mir, das hast du wol bewiset an dir. Du hast mich geschriben an din buch der gotheit, du hast mich gemalet an diner monscheit, du hast mich gegraben an diner siten, an henden und an fussen. Eya, erlobe mir, vil liber, das ich dich salben musse. 
não é completo em si mesmo ou um ser harmônico. Antes, para que Deus seja Deus, ele necessita do ser singular. Como um pressuposto, ele é uma ferida aberta, se abrindo para que os seres venham à existência: diz-se que a alma está enterrada nas feridas sagradas. Aos estigmas é dado um papel central, enquanto o lugar no qual o indivíduo ocorre e no qual é, também, separado e ligado a Deus. O fosso entre eles também constitui a possibilidade de um encontro. Se nos ativermos à idéia de que Deus e a alma tecem a sensibilidade juntos, eles têm que ser separados para ser o que são. A sensibilidade sempre inclui uma separação entre poder ser sentido e ser capaz de sentir. Mas como cada lado - também dentro de si e, de maneiras diferentes - duplica esta separação, eles encontram ainda outra proximidade e possibilidade de se aproximar do outro.

A ferida torna possível à alma ser um outro em relação a Deus - ser sentida - e sentir a si mesma. Mas isto significa dor, dado que a separação é dor. Contudo, assim como no parto, é uma dor que traz frutos, necessária para que um mundo de vivências venha a ser. No entanto, é também o início de uma possível consolação que eles, talvez, dêem ao outro. Então Deus a pergunta onde ela achará o bálsamo. O amor que existe através da ferida da carne e cria a separação - bem como a tensão erótica - os aproxima como a única possibilidade de consolação. Mechthild acha este bálsamo consolador ao rasgar o seu coração em dois, criando um fosso em sua carne enquanto ela é ambos vivenciada e vivenciante. Como tal ela duplica, em si mesma, o fosso entre os dois. Ela duplica a separação para poder se juntar a Ele e curá-lo. E Ele diz que ela só poderia ser um bálsamo se ela o deixar adentrar sua alma. Ela só pode acontecer nele se Ele acontecer nela. Se a primeira parte inclui a discussão sobre os sentidos, a

- Ja, wa woltistu die salben nemmen, herzeliebe?

- Herre, ich wolte miner sele herze inzwoi rissen und wolte dich dar in legen.

- So mohtest du mir niemer so liebe salben gegeben, als das ich ane underlas in diner sele muste sweben.

- Herre woltest du mich mit dir ze huse nemen, so wolte ich iemer me din arcedinne wesen.

- Ja, ich wil' [III:2]

Tradução para o inglês: Lord you are constantly lovesick for me. That you have clearly shown personally. You have written me into your book of the Godhead; You have painted me in your humanity; You have buried me in your side, in your hands and feet. Ah, allow me, dear One, to pour balsam upon you.

- Oh, one dear to my heart, where shall you find the balm? O Lord, I was going to tear the heart of my soul in two and intended to put you in it.

- You could never give me a more soothing balsam than to let me unceasingly lie weightlessly in your soul.

- Lord, if you were to take me home with you, I would be your physician forever.

- Yes, I want that. [...]' [III:2] 
relação aqui ocorre dentro de uma carne ferida que torna possíveis os sentidos. O pressuposto do ver é uma ferida em sua necessidade de algo visto. Mas como algo visto, a alma duplica esta ferida em sua capacidade de ver. A alma duplica a ferida divina em sua capacidade de ambos ser vista e ver. Ela repete a ferida em si mesma. Através desta ferida e distância dentro de si mesma, a alma alivia o divino, talvez porque suas feridas tornem possível se voltar para o divino. A ferida do divino torna o indivíduo possível. A alma repete esta ferida, o que a possibilita voltar para além do visto e criar uma relação com o divino. É este duplo ver que funciona como o bálsamo.

Eu sugeriria, aqui, que a alma não deve ser entendida em contraste ao corpo. A carne é, antes, o lugar no qual a ferida pode acontecer. A ferida seria, então, um nome para a alma. A alma duplica ou espelha a Deus, tanto como o capaz de ver quanto o visto, mas, ainda mais, duplica a Deus enquanto fosso entre estes. Por causa deste entrelaçamento não há nenhuma divisão definitiva entre o homem e Deus, mas, sempre, uma dependência mútua, uma relação entrelaçada onde eles se tecem um ao outro. Não pode haver um 'um elemento' na vida e no ser, visto que este 'um' já é, sempre, uma divisão imediata. O elemento do sentir é, de início, dividido e, portanto, não apenas si mesmo, mas entrelaçante e ansioso pelo outro.

Enquanto um corpo, o ser humano é, portanto, bifacetado - alma, como algo sentido e capaz de sentir. Mais comumente, fora a sua dimensão sensível e a espiritualização deste sentir que a conectaram com o divino. Neste texto, no entanto, é o corpo - inteiramente capaz de sentir - que dá à alma uma posição de destaque:

Quando eu reflito que a natureza divina agora inclui osso e carne, corpo e alma, então, eu me encontro suspensa em grande júbilo, muito além daquilo que eu mereço. Mas os anjos são, em grande medida, formados em acordo com a Santíssima Trindade, muito embora eles sejam espíritos puros. A alma, sozinha com sua carne, é senhora da casa no paraíso, senta-se ao lado do eterno Mestre da casa e lhe é parelha. [IV: 14] $]^{12}$

12 Texto original: Swenne ich das gedenke, das gotlich nature nu an ir hat bein und vleisch, lip und sele, so erhebe ich mich mit grosser vrode verre úber min wirdekeit. Aber der engel ist etlicher masse gebildet na der heligen drivaltekeit, doch ist er ein luter geist. Dú sele ist mit irem vleisch alleine husvro in dem himelriche und sitzet bi dem ewigen wirte, im selber allerglichest. [IV:14] 
Aqui está claro que a corporeidade de Jesus torna a similaridade a Deus completa. Jesus era corpo na trindade desde o seu fundamento e a sua corporeidade não foi a consequência da queda. Neste texto também fica claro que não há oposição entre 'alma' e 'corpo': 'a alma com sua carne' tem a posição de destaque. A alma, sem seu corpo, não é, portanto, alma, mas apenas outro anjo. Isto se desenvolve em outro verso:

[...] o mais nobre anjo, Jesus Cristo,

Que singra sobre os Serafins,

Que, com o seu pai, é inseparado,

Ele, hei eu, a menor das almas, de tomar nos braços,

Comê-lo e bebê-lo,

E fazer com ele o que eu quiser.

Isto nunca pode acontecer aos anjos.

Quão alto ele habite sobre mim [não importa],

Sua Divindade nunca estará tão distante,

Que eu não possa constantemente enlaçar meus membros com ele;

E eu nunca hei de esfriar.

O que me importa, então, o que os anjos acham? (II: 22) ${ }^{13}$

A descrição da comunhão, aqui, mostra que a exterioridade do corpo, sua capacidade de agir e ter poder, é central em Mechthild. Esta capacidade lhe dá uma intimidade e relação específicas com o divino. Novamente é o corpo mundano, um corpo que pode ser visto e que pode agir no mundo, que pode fazer o que os altos anjos não podem. Esta exterioridade do corpo está intimamente relaciona-

Tradução para o inglês: When I reflect that divine nature now includes bone and flesh, body and soul, then I become elated in great joy, far beyond what I am worth. But angels are to some degree formed according to the Holy Trinity, but they are pure spirits. The soul alone with its flesh is mistress of the house in heaven, sits next to the eternal Master of the house, and is most like him. [IV:14]

13 Texto original: Den werdesten engel Jhesum Christum, der da swebet oben Seraphin, der mit sinem vatter ein ungeteilet got mus sin, den nim ich minstú sele in den arm min und isse in und trinke in und tun mit im, swas ich wil. Das mag den engeln niemer geschehen. Wie hohe er wonet ob mir, sin gotheit wirt mir niemer so ture, ich musse ir ane unterlas allu mine gelide vol bevinden; so mag ich niemer mere erkulen. Was wirret mir denne, was die engel bevinden? [II:22] 
da à sua interioridade, ao calor e, portanto, com a vida do corpo que aqui se torna o encontro íntimo com o divino. Esta relação íntima e interior com Deus dentro do corpo é também o que constitui a possibilidade para que ela escreva:

Eu não sei como escrever nem, tampouco, o posso, ao menos que eu veja com os olhos de minha alma e ouça com os ouvidos de meu espírito eterno e sinta, em todas as partes do meu corpo, o poder do Espírito Santo. $[\mathrm{IV}: 13]^{14}$

Neste texto, os olhos da alma e os ouvidos do espírito têm um lado espiritualizado ou metafórico. Todavia, quando ela chega nos membros de seu corpo, não há espaço para metáforas. Sentir aqui se sobressai como o sentido mais próximo ao corpo. Se os olhos da alma e os ouvidos do espírito tornam algo presente, a sensação dos membros é a presença de onde elas partem. Isto é a vida presente que torna toda transcendência, criatividade e memória do ser humano possíveis. Este é o lugar no qual a alma nasce e se recebe a si mesma.

\section{O mundo entre nós}

Os sentidos são tratados, nos escritos de Mechthild, como as amas e ajudantes da alma. Ela também diz que o seu reino é a vista, o pensamento, a fala, a audição e o tato (I:46) Diferentemente dos cinco sentidos convencionais, olfato e paladar são, aqui, substituídos por pensamento e fala. Eu não penso que isto seja um mal-entendido, mas antes, que nos diz exatamente como Mechthild toma os sentidos, a saber, como um intelecto sensível ou uma sensibilidade intelectual. A sua busca pelo divino não é um esforço espiritual além ou distante da sensibilidade; antes, é por via dos sentidos que ela busca pelo divino:

Tradução para o inglês: [ ] the noblest angel, Jesus Christ, who soars above the Seraphim, who is undivided with his Father. Him shall I, the least of souls, take in my arms, eat him and drink him, and have my way with him. This can never happen to the angels. No matter how high he dwells above me, his Godhead shall never be so distant that I cannot constantly entwine my limbs with him; and so I shall never cool off. What, then, do I care what the angels experience? [II:22]

14 Texto original: Ich enkan noch mag nit schriben, ich sehe es mit den ogen miner sele und hore es mit den oren mines ewigen geistes und bevinde in allen liden mines lichamen die kraft des heiligen geistes.[IV:13] 
'A pessoa que ama a verdade gosta de rezar desta forma: 'Ah, querido Senhor, me conceda e me ajude para que eu possa sempre buscar-te, de uma maneira sagrada, com todos os meus cinco sentidos em todas as coisas [...] (VII: 15) ${ }^{15}$

Por meio dos sentidos ela pode achar Deus dentro das coisas e dos seres do mundo, mas não como uma coisa ou ser. Isto não significa que o poder transcendente deixa os sentidos e nem que apenas o que pode ser visto ou ouvido é aceito. Pelo contrário, atesta que os olhos da alma podem se mover para além do que é sensivelmente presente (II:2 e II:3). Nós poderíamos entender esta visão da alma exatamente como o poder transcendente que não nos prende à presente visão, mas tem a liberdade de se mover por dentro da memória, das visões de outros, da fantasia etc. Através desta capacidade, o ser humano também pode se voltar para a estrutura da sensibilidade ela mesma e refletir sobre esta habilidade. Mas em Mechthild tais reflexões não a conduzem para outro mundo. De modo diverso, ela vê o mundo de uma nova forma:

Então os sentidos dizem:

'Nossa senhora, a alma, dormira desde a infância;'

Agora, ela despertou, sob a luz do amor aberto.'

Nesta luz ela olha ao redor de si mesma para descobrir,

Quem é que aquele que se lhe revela,

E o que é isto que alguém lhe diz.

Tradução para o inglês: I do not know how to write, nor can I, unless I see with the eyes of my soul and hear with the ears of my eternal spirit and feel in all the parts of my body the power of the Holy Spirit. [IV:13]

15 Texto original: Der mensche, der die warheit minnet, der bittet gerne alsus: Eya lieber herre, gonne mir und hilf mir, das ich dich ane underlas suche mit allen minen fúnf sinnen in allen dingen heleklich [VII:15] 
Então ela verdadeiramente compreende,

Como Deus é todas as coisas em todas as coisas. [II:19] ${ }^{16}$

O olhar fixo e iluminado sobre o mundo, assim, vê os seres mundanos não como autossuficientes e autônomos, mas, antes, como ligados ao chão sem chão que também se estende para além deles e os une, ou seja, em relação ao divino transcendental e transcendente. Nós podemos também enfatizar o fato de, na passagem acima, serem os sentidos que nos dizem o que a alma vê. Que a alma esteja desperta e veja Deus, isto poderia compreendido como um evento para além da sensibilidade. Entretanto, dado que Deus aqui é vivenciado nas coisas, a sensibilidade ainda está ativa. Mechthild, desta forma, luta pela possibilidade de ver isto em todas as coisas, não apenas em algum objeto religioso específico, como os ícones.

Quando em um verso se diz que o seu reino de sensibilidade intelectual está ameaçado por perigos externos e deve ser protegido para que ele não caia vítima do diabo, este momento demoníaco pode ser entendido como a tendência de ver os seres como independentes e sem uma conexão a outras coisas e a um solo. De modo parelho, Mechthild nos adverte contra a ganância e a luxúria, que podem caracterizar a vida terrena. No entanto, em um texto que foca em tais avisos quanto às coisas terrenas, ela conclui, em acordo com o que diz o seu Deus, com uma advertência contra o oposto, a saber, contra deixar o mundo e amar apenas Deus:

Aqueles que conhecem e amam a nobreza de minha liberdade não suportam amar-me apenas por mim. Eles também devem amar-me nas criaturas. Deste modo eu mantenho o que é mais próximo a eles em suas almas.

Tradução para o inglês: The person who loves truth likes to pray thus: Ah, dear Lord, grant me and help me that I always seek you in a holy manner with all my five senses in all things [ ] [VII:15]

16Texto original: So sprechent die sinne: Únser vrowe, dú sele, hat gesclaffen von kinde; nu ist si erwachet in dem liehte der offener minne. In disem liehte sihet si sich al umbe, wie der si, der sich iro wiset, und was das si, das man ir zu sprichet. So sieht si werlich und bekennet, wie got ist allú ding in allen dingen [II:19] 
Um tema recorrente em Das fließende Licht der Gotheit é, com isto, a pergunta por como alguém deveria amar ao mundano. Este amor está intimamente relacionado à sensibilidade, mas uma sensibilidade que não é apenas sua. Ele não é apenas um encontro entre ela mesma e a coisa sentida, mas, de modo diverso, um encontro entre ela, o divino e o criado: 'Antes, na nobreza das criaturas, em sua beleza e utilidade, eu amarei a Deus e não a mim mesma.' [VI:5] ${ }^{18}$ A dação do mundo se estende para além dela mesma, para uma dação mais ampla; o que é dado a alguém está conectado à dação além deste indivíduo, acessível aos outros e, mesmo quando ela é uma vivência que não é, em nenhum aspecto, acessível aos outros humanos, ela não está sozinha nesta vivência: a dação sempre a transcende.

A posição de Mechthild implica que ela não se encontra entre o mundo e Deus, de modo que ela ou tem que estar de costas para os seres em sua busca por Deus ou de costas para Deus ao vivenciar o mundo. Pelo contrário, ela está posicionada de tal maneira que os seus sentidos podem atravessar as coisas e os seres que estão presentes aqui e agora, em direção aos seus pressupostos e interconexões, sem objetificar estes pressupostos. Os sentidos não devem estar direcionados em uma ou outra das duas direções opostas, mas pode abraçar ambas ao mesmo tempo. Quando ela toma parte da experiência do infinito, ela não a transforma em um objeto entre muitos, mas o sente como um aspecto central do finito. A mudança de direção pela qual a alma desperta passa não inclui um movimento do finito ao infinito, mas é direcionada às criaturas em sua direção a Deus. Ou, em uma linguagem filosófica: à coisa no mundo, em direção ao seu

Tradução para o inglês: Then the senses say: Our lady, the soul, has slept since childhood. Now she has awakened in the light of open love.In this light she looks around herself to discover Who that is who reveals himself to her, And what that is that one is saying to her. Thus does she see truly and understand How God is all things in all things. [II:19]

17 Texto original: 'Swer die edelkeit miner vriheit bekennet und minnet, der mag des nit erliden, das er mich alleine minne dur mich; mere er mus mich minnen in den creaturen; so belibe ich der nehste in siner sele.' [VI:4]

Tradução para o inglês: Those who know and love the nobility of my liberty cannot bear to love me only for my own sake. They must also love me in creatures. Thus do I remain what is most close to them in their souls. [VI:4]

18Texto original: 'Mere der edelkeit der creaturen, ir schoni und ir nutz - da wil ich got inne meinen und nit mich selben.' [VI:5]

Tradução para o inglês: Rather, in the nobility of creatures, in their beauty and usefulness, I shall love God and not myself.[VI:5] 
solo transcendental/transcendente através do qual a coisa transborda a forma a partir da qual ela é dada a mim.

De modo similar, ela diz, em um hino de agradecimento, que tal visão deveria permear todas as nossas ações. Isto é salientado em um texto que descreve como o ser humano está sempre unido a Deus, uma união que não acontece em algum paraíso distante, mas através do recebimento de dádivas mundanas que são dadas aos seres humanos:

Então nós louvamos o nosso Senhor, Deus, com todas as dádivas que ele já nos dera: nosso corpo e posses, amigos e parentes e todo o júbilo terreno o qual poderíamos desejar. Agindo deste modo, nós agradecemos a Deus por todas as dádivas que ele nos deu na terra para a alma e para o corpo. Assim, nos unimos a Deus, no amor por receber e em uma humilde gratidão. Daí, devemos pressionar todas as dádivas de Deus contra nosso coração. Assim, nosso coração se torna pleno de amor, nossos sentidos abertos e nossa alma tão resplandecente que olhamos para dentro do conhecimento divino como alguém que vê seu próprio reflexo em um luzente espelho. ${ }^{19}$

Deus, neste exemplo, denota uma dação que não podemos controlar. Ao nos abrirmos para a sensação de gratidão por ter uma vida humana, os sentidos são, novamente, transformados enquanto estão sendo abertos. A união com Deus é, aqui, um prazeroso gozo do mundo. Há também algumas formulações no texto de Mechthild que podem ser entendidas em uma maneira panteísta, como quando Deus diz: 'Eu sou em mim mesmo, em todos os lugares e em todas as

19 Texto original: so loben wir únsern herren got mit allen den gaben, die er úns ie gegab: unsern lip und gut, vrunde und mage und alle irdenische wollust, die wir begeren mohten. Hie mitte so danken wir gotte aller siner milten gaben, die er uns ie gegab in ertrich an libe oder an sele. Sus sin wir aber mit gotte vereinet in annemmelicher liebin und demutiger dankberkeit. Da mitte sollen wir alle gotz gaben in únser herze druken. So wirt únser herze minnenvoll, so werdent únser sinne geoffenet und so wirt únser sele also clar, das wir sehen in die gotlichen bekantnisse als ein mensche sin antlize besihet in eime claren spiegel. [VII:7]

Tradução em inglês: Then we praise our Lord God with all the gifts that he ever gave us: our body and possessions, friends and relatives, and all the earthly joy that we could desire. In so doing we thank God for all his generous gifts that he ever gave us on earth for body and soul. Then we are united with God in the love of receiving and in humble gratitude. We should thereby press all Gods gifts to our heart. Then our heart becomes full of love, our senses are opened, and our soul so resplendent that we look into divine knowledge like someone who sees his own countenance in a bright mirror. [VII:7] 
coisas, visto que eu sempre fui eternamente.' $[\mathrm{II}: 25]^{20}$ Deus é em si mesmo no mundo, ou seja, não em si mesmo para além do mundo. Este não é, no entanto, um panteísmo que denota que Deus se esgota no mundo. Está mais para um panenteísmo no qual Deus está presente nos seres, mas também os supera enquanto seu horizonte de transcendência.

Esta compreensão de Deus e da presença de Deus não é apenas a experiência pessoal de Mechthild; está conectada à sua escolha de vida como beguina. A sua posição filosófica influencia a sua vida prática ou o contrário: sua vida prática está expressa em seus escritos. Enquanto beguina ela estava, muito provavelmente, envolvida com diferentes atividades sociais e financeiras na cidade, já que as beguinas não se afastavam do mundo e se isolavam em um convento. A sua relação com o divino passava, ou era vivenciada, através da pressa da cidade. O seu trabalho no mundo não era apenas um ato de compaixão pelas criaturas que estavam presas no mundo, mas, antes, uma experiência do mundo como lugar onde a relação com o divino pode ser estabelecida, aproveitada e sofrida.

\section{Semelhança e Dissemelhança}

Em um texto bastante diferente [III:9] Mechthild nos dá a sua versão da criação. Ela descreve a criação como tendo se originado em um desejo erótico pela alma, ligado a Adão e Eva. Diz-se que os anjos são criados como um só espírito junto ao Espírito Santo, enquanto que o ser humano é criado em semelhança e oposição; enquanto o outro de Deus e enquanto sua esposa. O ser humano não é, como vimos anteriormente, inferior ao anjo, mas o amado de Deus. O humano é criado em semelhança à humanidade do filho, mas em alteridade em relação ao pai; enquanto seu amado. Em um texto Deus diz: 'Eu ansiei por ti antes do começo do mundo. Eu anseio por ti e tu anseias por mim. Onde dois ardentes desejos se encontram, aí o amor é perfeito.' [VII:16] ${ }^{21}$

Desde o início mais remoto ele é desejo. Como em qualquer desejo, há um impulso de tanto tragar o amado para dentro de si mesmo quanto de manter uma

20Texto original: 'Ich bin in mir selben an allen stetten und in allen dingen als ich ie was sunder beginnen.’ [II:25]

Tradução para o inglês: I am in myself in all places and in all things, As I always have been eternally. [II:25]

21Texto original: Ich habe din begert e der welte beginne. Ich gere din und du begerest min. Wa zwoi heisse begerungen zesamen koment, da ist die minne vollekomen. [VII:16] 
distância em relação ao amado para que ele seja ele mesmo. Antes da queda, a alma é a esposa de Deus e uma Deusa e os anjos servos dela. Através desta criação o ser humano passivamente recebe sua vida, mas isto, imediatamente, conduz à sua queda. À queda só é dada uma breve atenção, quando Deus reclama a respeito de suas ações dizendo: 'Ela decidiu não mais me permanecer similar' (III:9) ${ }^{22}$ Ela fora criada em dissonância a ele e, na queda, ela ativa o que recebera passivamente, e engendra a sua alteridade.

Apesar do Pai virar as costas para ela, o Espírito e o Filho nunca deixam de amá-lo e decidem salvá-la. $\mathrm{O}$ amor entre a alma e o divino não diminui, mas a tensão erótica cresce com a crescente distância. Neste texto, Deus é desejoso e, como tal, exige que a sua amada seja algo alheio a ele. $\mathrm{O}$ ser humano assume esta alteridade e a põe em movimento, o que implica a queda. A distância entre eles é criada, aqui, em duas etapas, uma de passividade e uma onde a atividade imanente na passividade é ativada. O entrelaçamento da sensualidade é formulada, aqui, em termos eróticos. $\mathrm{O}$ fosso dentro da rede da sensibilidade é o pressuposto da alteridade e o desejo é, portanto, organizado através de uma semelhança e dissemelhança simultâneas.

O encontro erótico completo, no qual os sentidos mundanos encontram seus limites, é trabalhado em I:44, um dos mais famosos versos de Das fließende Licht der Gotheit. Este texto é dramatizado e mitológico, e sua forma é influenciada por canções de casamento e poesias de amor cortês de seu tempo. Os sentidos têm um papel fundamental neste verso também. O trecho começa com o amante (Deus) tentando fazer contato com a sua amada (a alma) e a chamando. Os primeiros a ouvir seu chamado são os sentidos. Eles dizem à alma:

- Dama, tu deverias vestir-te.

- Queridas, para onde deveria estar me dirigindo agora?

- Nós certamente ouvimos, sussurrado por aí, que o príncipe pretende vir a ti no orvalho e no encantador

Tradução para o inglês: I longed for you before the beginning of the world. I long for you and you long for me. Where two burning desires meet, there love is perfect.[VII:16]

22 Texto original: Do wolte si mir nit langer glich wesen. [III:9] 
canto dos passados. Enfim, dama, não tardes $!^{23}$

O chamado não é aos sentidos, mas à alma. Mas são os sentidos que estão atentos ao chamado e eles a auxiliam enquanto ela se veste a camisa da humildade, o vestido da castidade e o manto do santo chamado. Ela vai ao local da reunião onde ela encontra o amante que a convida para dançar. Ela responde que, se ele cantar para ela, o seu deleite transcenderá todos os sentidos humanos. $\mathrm{O}$ encontro com o amante é, neste texto, uma jornada além ou über. Isto fora comumente entendido como o abandono de um lugar por outro. Mas eu preferiria compreendê-lo em reação ao grego hyper, que significa intensificação ou aprofundamento. Uma vez que a alma se torna ciente do divino ela, também, toma conhecimento das limitações dos sentidos e suas habilidades. $\mathrm{O}$ divino está na percepção, mas não pode ser vivenciado numa percepção. Este encontro amoroso é uma tentativa de aproximar os lados não dados do divino.

Após dançar, a alma é convidada a jantar. Ela está cansada e retorna aos sentidos dizendo-os que ela precisa descansar e esfriar um pouco. Os sentidos sugerem diferentes virtudes e estratégias cristãs, através das quais a alma pode descansar e nas quais eles podem tomar parte. A alma, contudo, só se satisfaz com o encontro erótico que está para além das estratégias sobre a castidade, sofrimento ou sabedoria ou atitude dos santos, dos anjos ou da criança. No entanto, o encontro erótico é, também, o único tipo de encontro que cegaria os sentidos. Neste encontro, a alma encontra a sua natureza e, muito embora os sentidos estejam cegos nesta união, ainda está em jogo uma sensação: ele queima e refresca e isto ainda é algo sentido, como ela explica aos sentidos:

- Não credes que eu o sinta intensamente?

Ele pode tanto queimar intensamente quanto refrescar consoladoramente.

Mas não ficai tristes!

Tradução para o inglês: She decided not to remain in my likeness. (III:9)

23Texto original: Vrowe, ir sollent úch kleiden. Liebe, wa sol ich hin? Wir han das runen wol vernomen, der fúrste wil úch gegen komen in dem in dem towe und in dem schonen vogelsange. Eya vrowe, nu sument nút lange![I:44]

Tradução para o inglês: -Lady, you should dress yourself. -Dear ones, where am I supposed to be going? -We have definitely heard it whispered about that the prince intends to come to you in the dew and in the delightful song of the birds. Alas lady, do not tarry! (I:44) 
Vós ainda havereis de instruir-me.

Quando eu retornar, certamente hei de precisar de vosso conselho,

Pois a terra é cheia de armadilhas. (I:44) ${ }^{24}$

E com esta promessa de retorno, é hora do encontro mais íntimo:

- Fiques, nobre Alma!

- O que me propões, senhor?

- Despes-te de tuas roupas!

- Senhor, o que acontecerá comigo, então?

- Nobre alma, tu és tão completamente conformada à minha natureza que a menor coisa não pode haver entre tu e mim. Nunca fora, antes, um anjo tão glorioso que a ele fora dado, em uma hora, o que lhe é dado em uma eternidade. Deste modo, tu deves deixar de lado ambos teu medo e tua vergonha e todas as virtudes externas. Ao invés disto, todas aquelas que, por natureza, tu carregas contigo deves fomentar para sempre. Estas são teu nobre anseio e teu desejo ilimitado. Estes eu hei de, para sempre, realizar com minha prodigalidade infinita.

- Senhor, agora sou uma alma nua e tu em ti mesmo és um Deus finamente adornado. Nosso quinhão compartilhado é a vida eterna sem morte.

Então uma calma abençoada, desejada por ambos, cai sobre eles. Ele se rende a ela e ela se rende a ele. O que acontece a ela, isto ela sabe, e com isto estou de acordo. Mas isto não pode durar muito mais. Quando dois amantes furtivamente se encontram, eles devem,

24 Texto original: Went ir, das ich nit enpfinde son wol? Er kan beide krefteklichen brennen und trostlichen kulen. Nu betrubent úch nit ze sere! Ir sollent mich noch leren. Swenne ich widerkere, so bedarf ich úwer lere wol, wan dis ertrich ist maniger strikke vol. [I:44] 
frequentemente, se separar um do outro. ${ }^{25}$

Neste encontro amoroso íntimo, a alma é afastada de todas as coisas como seres em particular e deixa de lado todas as virtudes culturais enquanto remove suas roupas. Ela abandona toda particularidade para poder se abrir àquele desejo esmagador e à sensação que é a sensação de sentir e que está, portanto, sobre (über) a experiência de sentido normal; para uma experiência de seu pressuposto. Esta intensificação apaga todas as distinções e torna as múltiplas percepções impossíveis. Apenas uma sensação ainda está aqui, a sensação do desejo entre os dois, ou seja, o fosso entre eles: a sensação do sensual enquanto tal. Isto também inclui um movimento além da linguagem e um narrador deve ser colocado na história. Mas a união entre Deus e a alma é como todas as outras uniões eróticas: temporária. Seguindo este encontro, ela carregará, a todo momento, a sensação de sensibilidade consigo em seu corpo talvez, simplesmente, porque ela está consciente dele.

Tradução para o inglês: Don't you believe I feel him intensely? He can both burn powerfully and cool consolingly. Now don't be overly sad.You shall yet instruct me. When I return, I shall certainly need your advice; For the earth is full of snares. [I:44]

25 Texto original: Stant, vrowe sele! Was gebútest du, herre?Ir sont úch usziehen!Herre, wie sol mir denne geschehen?Frow sele, ir sint so sere genatúrt in mich, das zwúschent úch und mir nihtes nit mag sin. Es enwart nie engel so her, dem das ein stunde wurde gelúhen, das úch eweklich ist gegeben. Darumbe sont ir von úch legen beide vorhte und schame und alle uswendig tugent; mer alleine die ir binnen úch tragent von nature, der sont ir eweklich vulen. Das ist úwer edele begerunge und úwer grundlose girheit; die wil ich eweklich erfúllen mit miner endelosen miltekeit.Herre, nu bin ich ein nakent sele und du in dir selben ein wolgezieret got. Unser zweiger gemeinschaft ist das ewige lip ane tot. So geschihet da ein selig stilli nach ir beider willen. Er gibet sich ir und si git sich ime. Was ir nu geschehe, das weis si, und des getroste ich mich. Nu dis mag nit lange stan; wa zwoi geliebe verholen zesamen koment, si mussent dike ungescheiden von einander gan.

Tradução para o inglês: Stay, Lady Soul. - What do you bid me, Lord? - Take off your clothes. - Lord, what will happen to me then? - Lady Soul, you are so utterly formed to my nature that not the slightest thing can be between you and me. Never was an angel so glorious that to him was granted for one hour what is given to you for eternity. And so you must cast off from you both fear and shame and all external virtues. Rather, those alone that you carry within yourself shall you foster forever. These are your noble longing and your boundless desire. These I shall fulfill forever with my limitless lavishness. - Lord, now I am a naked soul and you in yourself are a well-adorned God. Our shared lot is eternal life without death Then a blessed stillness that both desire comes over them. He surrenders himself to her, and she surrenders herself to him. What happens to her then she knows and that is fine with me. But this cannot last long. When two lovers meet secretly, they must often part from one another inseparably. [I:44] 


\section{Conclusão}

O corpo é, em muitas práticas cristãs, o que deve ser disciplinado a silenciar e os sentidos algo que deve ser transcendido. No texto de Mechthild o corpo é, também, por vezes, descrito como uma prisão. Sua solução não é abandoná-lo, mas estar mais atento a ele, ou seja, não seguir o seu desejo em direção ao mundo de coisas e seres desconexos, mas adentrar esta estrutura desejante de deleite e sofrimento. Tal atenção não apenas significa viver a atividade do corpo sensível, mas também estar atento à passividade; a como a sua sensibilidade é dada. Disciplinar inclui a contenção das apreensões para poder encontrar um outro sentir, um sentir da sensibilidade. Não se deve virar as costas para o mundo, nem, tampouco, se perder no mundo. A vivência do mundo deveria, pelo contrário, ser aprofundada e intensificada, vivenciando a interconexão e os pressupostos do mundo.

A alma que ama o divino e vive próxima a suas próprias pressuposições tem um corpo sensível à transcendência. Ela está atenta a dimensões divinas: o não visto no sentir, no comer, no sofrer etc. O Corpo sensível enquanto presença do aqui e agora inclui a presença da ausência, do desejo pelo que não é presente e a possibilidade de ter outro futuro, bem como sentir de uma maneira diferente, notando novas coisas no presente.

A sensibilidade torna-se o caminho entre o corpo enquanto um objeto - como estático e algo sentido - e a alma transcendente que inclui o que não é dado no presente. A alma que fala no texto de Mechthild não deve ser entendida em oposição ao corpo. Ela é, ao invés disto, uma alma corporificada e capaz de sentir, tanto quanto a sua sensibilidade é uma sensibilidade intelectual. Neste sentido, o corpo vivo está presente e ativado e suas vivências são intensificadas pela jornada da alma rumo a Deus. Finalmente, no encontro erótico, o campo de tensão, fosso e desejo entre a alma - enquanto um sentir sentido - e seu Deus - enquanto sentir (anônimo) para além do sentir - é a única sensação remanescente. Isto é a intensificação da sensibilidade. 
ALVILDA PETROFF, Elizabeth. Body and Soul: Essays on Medieval Women and Mysticism. New York: Oxford University Press, 1994.

BEAUVOIR, Simone. The Ethics of Ambiguity. Secaucus: Citadel Press, 1948.

BORNEMARK, J. Ambiguities of the human body in phenomenology and Christian mysticism. In: Ola Sigurdson, Marius Timmann Mjaaland \& Sigridur Torgeirsdottir (eds.). The Body Unbound: Philosophical Perspectives on Religion, Embodiment, and Politics. Cambridge: ambridge Scholars Publishing, 2010. 73-88.

BYNUM, Caroline. Fragmentation and Redemption: Essays on Gender and the Human Body. Nova York: Zone Books, 1991.

HOLLYWOOD, Amy. The Soul as Virgin Wife: Mechthild of Magdeburg, Marguerite Porete and Meister Eckhart. Londres: Notre Dame, 1995. (ND Studies Spirituality \& Theology v.1.)

HUSSERL, Edmund. On the Phenomenology of the Consciousness of Internal Time [1893-1917]. Dordrecht, 1991.

JASPERS, K. Philosophy. Chicago: Chigago University Press, 1969, Philosophy, v.1.

KIERKEGAARD, Søren. The Concept of Anxiety. Princeton: Princeton University Press, 1981.

MAGDEBURG, Mechthild. Das fließende Licht der Gottheit. Frankfurt: Deutscher Klassiker Verlag, 2003. Tradução por Gisela Vollmann-Profe.

MERLEAU-PONTY, Maurice. The Intertwining: The Chiasm' in: The Visible and the Invisible. Evanston: Northwestern University Press, 1968.
MURDOCH, Iris. Existencialists and Mystics: Writings on Philosophy and Literature. Londres: Chatto \& Windus, 1997.

RUH, Kurt. Beginenmystik: Hadewijch, Mechthild von Magdeburg, Marguerite Porete. Zeitschrift für Deutsches Altertum und Deutsche Literatur. Wiesbaden: Steiner, 106, 265-277. 1977.

SCHELER, Max. The Human Place in the Cosmos. Evanston: Northwestern University Press, 2009.

SCHMIDT, Margot. Versinnlichte Transzendenz bei Mechthild von Magdeburg. In: Dietrich Schmidtke (ed.). Minnichlichiu gotes erkennusee: Studien zur frühen abendländischen Mystiktradition. Stuttgart-Bad Cannstatt: Frommann-holzboog, 1990. 61-88.

TOBIN, Frank. The Flowing Light of the Godhead. Nova York: Paulist Press, 1998. Tradução por Frank Tobin.

WEBSTER Marilyn. Mechthild von Magdeburg's Vocabulary of the Senses. Amherst: Univesrity of Massachusetts, 1996.

WENTZLAFF-EGGEBERT,Friedrich-Wilhelm. Deutsche Mystik zwischen Mittelalter und Neuzeit: Einheit und Wandlung ihrer Erscheinungsformen. Berlin: De Gruyter, 1969.

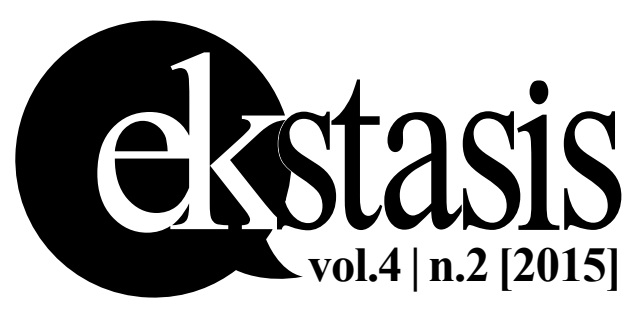

